\title{
Practice and Exploration of Psychological Consultation in the Platform Construction of Community Youth Club
}

\author{
Dehao Qu \\ School of Social Sciences \\ Tsinghua University \\ Beijing, China
}

\begin{abstract}
Mental health of adolescents is one of the important factors influencing social development. As an important part of mental health service, psychological consultation needs to establish close relationship with community, in order to timely, ceaselessly and effectively serve adolescents. As the platform of regional activities for adolescents and the regional primary-level organization, Community Youth Club avails the penetration of psychological consultation in communities and connects adolescents. Practice and explorations on constructing primary-level platform of psychological consultation service, promoting its development and training professionals of psychological consultation are analyzed.
\end{abstract}

Keywords-social governance; community youth club; mental health service; adolescents; social work

\section{INTRODUCTION}

At the end of 2016, National Health and Family Planning Commission of the People's Republic of China united with 22 national ministries and commissions such as the Propaganda Department of the Central Committee of the CPC to print and distribute the Guidance on Strengthening Mental Health Services (hereinafter referred to as "Guidance"). As the first macro guidance to strengthen mental health services, the Guidance further closely connects mental health service with social work and defines specific paths and methods for professional social work to participate in mental health service, in order to promote the significant development of mental health service and social work. The Guidance proposes, "mental health is significant public health issue and social issue that influences economic and social development", advocates roundly strengthening mental health service and gradually improving the social service system of mental health, meanwhile emphasizes psychological consultation is an important part of mental health service. The Guidance proposes specific methods to guide main groups of mental health service. In order to develop the mental health education for adolescents, the Guidance requires organizations like the Communist Youth League to unite with school, family and society and organize activities in order to promote mental health.
At present, the mental health status of Chinese adolescents isn't optimistic. Influenced by family, school, society and individual difference, adolescents suffer from stress. Mental health of adolescents faces great challenges, so increasing demands for psychological consultation exist. However, the construction of mental health service system in communities is incomplete. Meanwhile, problems exist in infrastructure construction, talent team construction and development forms and effects of psychological consultation. The Party and the country advocate the transformation from social management to social governance. As assistant and reserve force of the Party, the Communist Youth League explores and practices in improving the service system of mental health. The most typical example is that psychological consultation is introduced to the platform construction of Community Youth Club. The integration of psychological consultation and Communist Youth League includes system planning and material support. But it is still at the initial stage and needs further exploration and development to realize effective application of psychological consultation to the platform of Communist Youth League, in order to improve mental health status and prevent psychological problems even diseases of adolescents.

\section{InTRODUCTION TO MENTAL HEALTH OF ADOLESCENTS AND SERVICES}

\section{A. Introduction to Mental Health Status of Adolescents at Present}

Mental health of adolescents guides their learning and growth. However, at present, the mental health status of adolescents is severe. According to researches and reports at abroad, adolescents under 18 years old who have emotional and behavior problems account for 11 percent to 26 percent, who have serious or long-term psychological problems account for 3 percent to 6 percent (Zhang Haixia, 2010). Because of improper family education, lack of family structure, great academic pressure, bad social environment and internet culture, the mental health status of Chinese adolescents isn't optimistic, either. In 2010, scholars carried out sample survey for 16,472 primary and middle school students in five areas. The results indicate primary school 
students who have abnormal mental and behavior disposition and serious mental and behavior problems account for 16.4 percent and 4.2 percent respectively; middle school students who have abnormal mental and behavior disposition and serious mental and behavior problems account for 14.2 percent and 2.9 percent respectively; high school students who have abnormal mental and behavior disposition account for 14.8 percent (Shen Jiliang, 2002). If adolescents with psychological problems fail to receive timely and effective mental health service, it will influence their positive personality shaping and confidence in the future. If adolescents suffer from serious psychological problems for a long time, they may have negative induced emotions such as sense of helplessness, anxiety even suicidal tendency. They will do harm to themselves and people around them, even have adverse effects on social development.

\section{B. Compare the Construction of Mental Health Service System in Communities at Home and Abroad}

Mental health services in communities are of great importance to guarantee mental health of community residents. As the country that first establishes mental health service system in communities in the world, America has provided mental health services in communities in 1965 (Wang Ping, 2015), even establishes mental health service system in communities especially for adolescents. In 1984, National Institute of Mental Health opened "Child and Adolescent Service System Program, CASSP”. In 1994, relevant functional departments of federal government further established comprehensive program of mental health service in communities for children and their families, which symbolizes child and adolescent mental health service system based on communities in modern sense is formally established in America. So far, Federal funds have established 126 adolescent mental health service centers through direct funding to provide mental health services for 78,000 adolescents and their families. At the meantime, there are other service centers established by state government, county government and other funds. For example, organizations established in New York provide mental health services for 100,000 children and adolescents annually. With huge amount, they have professional service quality. The core principle of service centers is: base on communities and meet demands of patients and their families. Most adopt the "Wrap-around process" and unite service organizations in communities to serve through cooperating with families (Qiu Chengping, 2008), in order to ensure all services are suitable for service objects. Furthermore, it effectively unites educational institutions, medical institutions, welfare institutions and judicial organs that serve adolescents in communities to provide mental health services and furthest exploits their advantages. Subsequently, Canada, Japan and Britain establish related organizations in succession and regularly hold meetings.

At present, the mental health service systems in communities of most developed countries have been as sound as a bell. They prevent and treat psychological diseases, relieve pressure of families and society exerted by psychiatric patients as well as effectively improve mental health status of residents. In comparison, at present, the mental health service in communities of our country is still at initial stage. Although first-tier cities have tried to construct mental health service systems, problems exist such as the infrastructure construction is not in place, professionals are inadequate, the publicity of mental health knowledge is limited, and the service forms are single and ineffective. For example, in popularization and publicity of mental health knowledge, traditional ways like bulletin board, blackboard newspaper and publicity materials are adopted in communities, and the themes are outdated without practical application value, at the same time fail to meet real demands of adolescents. Incomplete publicity makes adolescents do not identify psychological consultation. No adolescents do psychological consultation, so staff cannot know more about mental health status of adolescents and fail to gather experience in psychological consultation. Our country is at the important stage with rapid development of social civilization and has numerous adolescents. It is of great importance for social development in our country to pay attention to mental health of adolescents and establish mental health service system for adolescents in communities in accordance with Chinese conditions.

\section{Basic Information of Community Youth Club}

Community Youth Club refers to regional activity platform constructed in accumulation area where young people and adolescents live and work, and the regional primary-level youth and adolescent organization subordinate to the Communist Youth League. "Regional activity platform" means providing integration into city life, entertainment, educational training, psychological consultation, law popularization and protection of legal rights; "regional primary-level youth and adolescent organization" refers to the place that depends on primarylevel communal facilities and daily activities of adolescents and provides for them to communicate and form organization.

In continuously expanding service type and constructing infrastructures, the Community Youth Club also trains professional talents to do social work for youth, and they are called "full-time social workers of Community Youth Club" who do psychological consultation for adolescents. The Guidance also emphasizes professional social work shall provide mental health service and improve its system and clearly proposes professionals for social work in mental health must be trained. The construction of Community Youth Club effectively meets requirements of adolescents in learning, entertainment and participation. At the meantime, it provides a new path that deserves exploration for the development of psychological consultation among adolescents.

\section{APPLICATION OF PSYCHOLOGICAL CONSULTATION IN THE PLATFORM CONSTRUCTION OF COMMUNIST YOUTH Club}

As regional youth organization that provides psychological consultation for adolescents, at the initial period of construction, the Community Youth Club takes 
psychological consultation as one of the eight main services provided for adolescents. Specific measures are taken in constructing primary-level platform of mental health service, promoting psychological consultation and training professionals of psychological consultation.

\section{A. Embedded Construction}

"Embed" is first proposed by Hungarian ideologist Karl Polanyi on the basis of "defend the society" in the research field of social sciences, and is used by Granovetter to systematically analyze economic activities and the reality of social relations (Huang Chuanli, 2013). According to the researches of predecessors, scholars of our country further define the concept of "embed", namely the process and state that one thing enters another thing, meanwhile propose four elements of embedded model, including embedded subject, embedded object, embedded process and embedded effect (Wang Chunhui, 2016).

According to this theory, the analysis that the Community Youth Club integrates in communities through "embedded" construction is as follows: embedded subjects are professionals in psychological counseling room and providing psychological consultation (including full-time social works or psychological consultants). In the construction, the location of Community Youth Club is uniformly stipulated as "indoor activity space not lower than 50 square meters", and space for psychological consultation is provided near the activity space; embedded objects refer to primary-level communal facilities (such as community center, cultural and sports center) and space for daily activities of adolescents; embedded process is very long. Community Youth Club piloted from 2010. Explicit construction and assessment criterions appeared in 2014. The requirement of "construct psychological counseling room" was proposed in this period. Obstacles exist in site selection and construction. At present, although more than 500 Community Youth Clubs of Beijing have psychological counseling rooms, but they are not specially designed for adolescents but for all community residents. According to the embedded effect, on one hand, the usage rate of public facilities in communities is obviously improved; on the other hand, it provides convenience for adolescents to participate in psychological consultation. Except for providing personal psychological consultation, the place also meets the demands of carrying out group psychological counseling, constructing a flexible and practical service and publicizing platform for psychological consultation to root and sprout in communities.

\section{B. Project Operation}

"Project operation" first prevails in NGO, refers to the work patter that turns work tasks and goals into one or multiple projects and operates through project management (Liu Qingyuan, 2009). In recent years, more and more government sectors refer to it because it has clear objectives, procedures and is operable and appreciable. Government provides certain amount of money for social organizations or social work institutions through purchasing services. Social organizations or social work institutions operate specific projects. Taking Dongcheng district of Beijing city as an example, the Community Youth Club established in Dongcheng district has received financial support from competent organization since 2014. The Communist Youth League of Dongcheng district encourages Community Youth Club through the innovation project of "One Club and One Brand" to plan projects that meet actual demands of adolescents. For the projects that get approved and provide services for adolescents, the Communist Youth League of Dongcheng district will provide financial support for Community Youth Club to support the projects. In the past few years, increasing attentions are paid to mental health problems of adolescents, so the Communist Youth League also advocates social service projects of psychological consultation. For example, lecture on mental health of adolescents named "Star Light Youth Protecting Action" has become one of the brand activities of Communist Youth Club carried out regularly. Some Community Youth Clubs integrate various forms of activity in projects. For example, invite psychological consultants to communities and provide service points in community that adolescents gather to carry out psychological consultation for them. It solves mental health problems for adolescents and effectively improves the influence of psychological consultation among community residents.

\section{Professional Training}

The training of professionals that provide mental health service is the important guarantee for effective psychological consultation. Scholars carry out sample survey of structure of personnel who provide mental health service in communities of Beijing. The results show: most people providing mental health service in communities have junior college degree and account for 44.9 percent; only 4.2 percent has psychological consultant certificate; part-timers account for 56.3 percent, and full-timers account for 43.7 percent (Zhang Wenlu, 2012). Obviously, personnel providing mental health service in communities have low professional ability. The high proportion of part-timers reflects inadequate attentions are paid to mental health services and the service object has low daily requirement of psychological consultation. The appearance of full-timer social workers of Community Youth Club greatly improves the personnel structure. Beijing Adolescent Social Work Association sets up strict access permission mechanism for full-timers of Community Youth Club. Full-time social workers must take the entrance examination organized by the association. The contents of examination cover social work and theories of psychological consultation. Except for the entrance examination, in daily work, the supervisors of social work provide at least one training course of psychological consultation for social workers regularly. Social workers participate in large-scale learning and training activity organized by the association per quarter, including group psychological consultation. They can learn knowledge and skills of group psychological consultation in firsthand experience. Furthermore, the assessment criteria for full-time social workers contains specific standard of psychological consultation. Each fulltimer of Communist Youth Club must assist or carry out psychological consultation for no less than ten adolescents annually and take corresponding records and conclusion. It 
supervises and urges social workers to provide psychological consultation in daily life.

\section{OPPORTUNITIES AND CHALLENGES OF \\ PSYCHOLOGICAL CONSULTATION IN THE PLATFORM CONSTRUCTION OF COMMUNITY YOUTH CLUB}

Many practices of psychological consultation are carried out in the platform construction of Community Youth Club but they are superficial. At present, the psychological consultation provided by Community Youth Club is at the initial stage and faces problems. Integration of psychological consultation and social work for adolescents and application need further exploration and development in the platform construction of Community Youth Club.

\section{A. Existing Problems}

1) Infrastructure construction is unsound: Community has great varieties of work and complex personnel structure. The integration of psychological consultation in communities through Communist Youth Club is gradual. At present, although Community Youth Clubs construct psychological counseling rooms according to the requirement, most become formalistic. Interior decoration and allocation of tools for psychological measurement and psychotherapy have large room for improvement. According to the visiting and the investigation, the construction of hardware environment is incomplete and the usage rate of psychological counseling room is low. Although Community Youth Club invests capitals in psychological consultation, because of the diversified and complicated work in communities, the funds for psychological consultation may be used to support other work. The fund flow cannot be guaranteed.

2) Social workers have weak professional ability: Because of low salary and unclear career development direction, most full-timers of Community Youth Club have first degree of junior college and below. Few have background of psychology and social work. Although in recent years, relevant departments encourage full-time social works to take the examinations related to social work and psychological consultant and learn professional theoretical knowledge after work, most full-timers of Community Youth Club have weak professional ability of psychological consultation. Besides, most full-time social workers work behind closed doors and engage in idle theorizing, know little about basic situation and actual demands of adolescents, so they fail to provide effective psychological consultation.

3) Lack publicity and education of psychological consultation: Nowadays, because adolescents lack ideas about psychological health and are afraid of being discriminated as "patients", few of them will actively seek help from personnel of psychological consultation. Most adolescents fail to pay attention to mental health. They deceive themselves and intentionally or unintentionally neglect psychological problems. On the other hand, the way of publicity of mental health is too single. The Community Youth Club often publicize through pasting documents and pictures on the bulletin board, difficult to attract attentions of adolescents.

\section{B. Workable Proposals}

1) Adjust ways of psychological consultation: Hardware construction requires long-term promotion, but software construction can make up for the deficiencies caused by unsound hardware construction. On the basis of the existing basic individual psychological consultation, Communist Youth Club can adjust activity design and carry out activities such as lectures of crisis intervention and mental health knowledge according to demands of adolescents. Meanwhile, they can integrate social work and awareness of group psychological consultation in daily activities and serve more adolescents through limited number of talents of psychological consultation.

2) Change the training mode of full-timers: On one hand, raise the admittance threshold of full-timers and formulate safeguard and incentive mechanism matched with their professional quality, in order to attract more talents to participate in psychological consultation and mental health service for adolescents in communities; for full-timers of Community Youth Club, management organizations should integrate and coordinate and expand professional resources of psychological consultation, provide more systematic and professional theoretical training and opportunities of clinical practical for full-time social workers, in order to make them apply what they learn.

3) Carry out publicity and investigation of psychological consultation: Seizing psychological needs of adolescents is the key to future development. The Community Youth Club should investigate psychological needs of adolescents through questionnaire and interviewing and summarize their characteristics. Adolescents with not serious psychological problems should be guided; close attentions should be paid to those with serious psychological problems. At the same time, Community Youth Club should take the initiative to publicize mental health knowledge through various forms, improve mental health literacy of adolescents and promote adolescents to establish positive outlook on mental health.

\section{CONCLUSION}

Mental health of adolescents and the construction of mental health service system in community are important issues of social work. Although compared with developed countries, our country is at the initial development stage of mental health service and has unsound planning and construction, the construction of Community Youth Club provides a new opportunity. At present, psychological consultation has integrated with Community Youth Club, including the construction of embedded primary-level platform of psychological consultation, project-oriented 
psychological consultation and training of professional talents in psychological consultation. It avails the penetration of psychological consultation in communities and the improvement of it among adolescents. Although the application of psychological consultation to platform construction of Community Youth Club has defects such as the infrastructure is unsound, the professional level of workers is low and the ways of publicity are single and education deficiency exists, it can be improved. The service mode of psychological consultation will be more diversified and pertinent after adjustment; the mechanism of introducing full-time social workers needs improvement and the training mode must base on the practice; psychological consultation needs further publicity and carries out macro control of service area, in order to gradually complete the mental health service system in community, give full play to the important role of psychological consultation in mental health of adolescents and let them grow healthily.

\section{REFERENCES}

[1] Huang Chuanli. Research on Integration of Professional Social Work in Public Service in Communities [J], Journal of Sichuan University of Science and Technology: 2013, 28(2): 24-28

[2] Liu Qingyuan. Current Situation of Service System of Psychological Health in Communities of American Children and Adolescents and Thinking [J], Journal of Social Work (Practice Edition): 2009(8): 1721

[3] Qiu Chengping, Du Liqin. Current Situation of Service System of Psychological Health in Communities of American Children and Adolescents and Thinking [J], Chinese Mental Health Journal, 2008, 22(3): 220-223

[4] Su Xiaocen, Ye Yiduo. Priority Development of Psychological Consultation in Psychological Service in Communities of Our Country [J], Journal of Fujian Medical University: 2010, 11(3): 12-14

[5] Wang Chunhui. Embedded Model of Social Work Service for Adolescents in Communities-Taking the Community Youth Club of Beijing as an Example [J], Beijing Youth Research: 2016(3): 92-98

[6] Wang Ping, Zhang Hui, Zhang Bin. Comparative Research of Mental Health Service in Communities at Home and Abroad [J], China Medical Herald: 2015, 12(29): 151-155

[7] Zhang Haixia, Zhang Tao. Discussion on Influence Factors of Psychological Health of Adolescents [J], Education and Teaching Research: 2010, 24(2): 26-28

[8] Zhang Wenlu. Research on Capacity of Mental Health Service in Communities of Our Country [D], Wuhan: Huazhong University of Science and Technology, Social Medicine and Health Service Management, 2012. 